\title{
Drying Characteristics of Blackberry Fruits in a Convective Hot-air Dryer
}

\author{
Maksut Barış Eminoğlu, Uğur Yegül ${ }^{1}$, and Kamil Sacilik \\ Department of Agricultural Machinery and Technologies Engineering, \\ Faculty of Agriculture, Ankara University, 06135, Ankara, Turkey
}

Additional index words. activation energy, dryer, effective diffusivity, hot air, model, moisture content

\begin{abstract}
In this study, blackberry fruits were dried in a pilot-scale hot-air dryer to identify the drying characteristics of the fruits. The air velocity was set as $1 \mathrm{~m} \cdot \mathrm{s}^{-1}$, and the temperature range was set as 54 to $75^{\circ} \mathrm{C}$. Fick's law of diffusion was used to describe heat transfer during the decreasing rate period. Effective diffusivity values were calculated, and the Arrhenius constitutive model was used to describe the temperature dependence of these values. The Page, logarithmic, approximation of diffusion, two-term, and Midilli et al. models were used to fit the experimental data. A nonlinear regression analysis was used to calculate rate constants and model coefficients. The present findings revealed that among the tested models, the Midilli et al. model best described the experimental data; therefore, it was concluded that the model could be used to describe the drying characteristics of blackberry fruits.
\end{abstract}

Blackberry (Rubus sp.) fruits are rich in phenolics (flavanols, anthocyanins, procyanidins, and chlorogenic acid), which are compounds that are highly active and have several health benefits; therefore, they are mostly used as dietary antioxidants (Moure et al., 2001; Reáteguia et al., 2014). Blackberries are mainly used as frozen, dried, or canned foodstuffs. Fruits are also processed into juice, jam, or jelly. Such processes prolong the storage duration and shelf life of these products (Rickman et al., 2007). Drying, which is the oldest method of preservation for various fruits, involves the process of reducing the moisture content or water activity of the fruits. The final quality is designated by the method of drying, the moisture level of the final product, packaging (regular or modified atmosphere packaging), and storage duration and conditions (Wu et al., 2010). In Turkey, there is an increasing demand for functional foods, especially for blackberries, because of the bioactive substance composition of these fruits.

Much of the weight of fresh fruit comes from its water content. Therefore, blackberry fruits have greater metabolic activity than other functional foodstuffs. Such metabolic activity, especially ethylene synthesis, continues after the harvest of the fruits, thus leading to their perishing and loss of flesh firmness within a short storage time (Atungulu et al., 2004). Therefore, the moisture content of fruits is reduced to prevent the growth and development of microorganisms, thereby prolonging storage duration and shelf life of the final products.

\footnotetext{
Received for publication 17 May 2019. Accepted for publication 17 June 2019.

${ }^{1}$ Corresponding author. E-mail: yegul@ankara. edu.tr.

This is an open access article distributed under the CC BY-NC-ND license (https://creativecommons. org/licenses/by-nc-nd/4.0/).
}

Drying is the basic process used to reduce moisture levels of the fruits; however, sundrying is a difficult process because of undesired changes in weather that can occur and lead to differences in quality attributes of the final product (Maskan, 2000). The primary goal of drying is to reduce the moisture level of agricultural products to a certain extent to minimize ongoing reactions and prevent microbial deterioration (Krokida and Marinos-Kouris, 2003).

The primary goal of commercial blackberry producers is to obtain high-quality dried fruits by using different methods of drying. The method used for drying significantly influences the quality attributes of the final product. Sun-drying is the most common method used for drying blackberries. The sun-drying process takes longer than mechanical drying, and it involves the product being exposed to various contaminants, pests, and disease agents, such as dust, birds, rodents, and microorganisms. Such contaminants may result in significant reductions in the quality of the final product. Therefore, mechanical drying, especially hot-air-drying, is used to overcome the apparent problems of sun-drying. Hot-air-drying can be used reliably for blackberry drying in large quantities and shorter periods without any negative impacts on the final product quality because the method does not rely on weather conditions and the products are not exposed to external factors (Tunde-Akintunde et al., 2005).

The drying characteristics of biological materials should be well-comprehended to achieve the best results. A literature review revealed that there have been no studies of the drying characteristics of blackberry fruits or drying systems for blackberries. Therefore, the present study was designed to determine the drying characteristics of blackberry fruits. A convective hot-air dryer was used to calculate effective diffusivity, and the activation energy of the fruits and available models were used to fit the experimental data and identify the best model for representing the dry characteristics of blackberry fruits.

\section{Materials and Methods}

Blackberry fruits used in the present experiments were supplied by the local markets of Ankara, Turkey. Experimental samples were stored in a refrigerator at $4{ }^{\circ} \mathrm{C}$ until the tests were performed. Fruits of uniform size and shape and without any visual defects were selected for the experiments. The average fruit dimensions along the principles axis were $23.6 \mathrm{~mm}, 20.6 \mathrm{~mm}$, and $19.8 \mathrm{~mm}$. Samples were dried in an oven at $70{ }^{\circ} \mathrm{C}$ for $24 \mathrm{~h}$ to obtain the initial moisture content of the fruits (AOAC, 1990). Experiments were repeated three times. The initial moisture content of the samples was $465.93 \%$ d.b. ( $82.33 \%$ w.b.).

The laboratory-scale convective hot-air dryer used in this study had dimensions of $57 \mathrm{~cm} \times 68 \mathrm{~cm} \times 57 \mathrm{~cm}$ (height $\times$ width $\times$ depth) (Fig. 1). The experimental dryer was equipped with a blower fan, heater, and weighing apparatus. Air flow rates were adjusted with a variable transformer that altered fan speeds. Constant airflow was applied throughout the experiments. A perforated basket $\left(576 \mathrm{~cm}^{2}\right)$ was used to hold the samples in the dryer. Moisture loss of the fruits was measured by using a load cell and recorded and transferred to a personal computer with the aid of special software (Sacilik et al., 2010).

Experiments were conducted at a constant air flow rate $\left(1 \mathrm{~m} \cdot \mathrm{s}^{-1}\right)$ and different drying air temperatures $\left(54,61,68\right.$, and $\left.75^{\circ} \mathrm{C}\right)$. When the system reached a steady state of operation at the set temperature, blackberry samples were uniformly placed as a thin layer of product in the perforated basket. During each experiment, $150 \mathrm{~g}$ of blackberry fruits were used. During the drying process, the weight loss of samples was recorded every $5 \mathrm{~min}$ with special software. Resulting data were used to draw drying curves at each temperature. Experiments were performed until the samples had a constant weight. Dried samples were cooled for $30 \mathrm{~min}$ at room temperature. Then, cooled samples were packed in low-density polyethylene bags. All experiments were replicated three times.

Resultant data were analyzed to model the process of drying and to determine the drying characteristics of the fruits. Experimental drying data for blackberry fruits were fitted to five well-known drying models used for different fruits (Table 1).

A moisture ratio of the product was calculated by using the following equation:

$$
M_{R}=\frac{M-M_{e}}{M_{0}-M_{e}}
$$

where $M_{R}=$ moisture ratio, $M=$ moisture content at any time, $M_{e}=$ equilibrium moisture content, and $M_{o}=$ initial moisture content.

Because the relative humidity is continuously fluctuating within the dryer, $M_{R}$ was reduced to $M / M_{0}$ (Diamente and Munro, 
1993). A nonlinear regression procedure was used to calculate rate constants and model coefficients. A quasi-Newton numerical method was used to estimate parameter values. Coefficient of determination $\left(R^{2}\right)$, root mean square error $\left(E_{R M S}\right)$, mean relative percent deviation $\left(E_{M D}\right)$, and reduced chisquare $\left(\chi^{2}\right)$ were used to check the model validity and compare the models. The parameters used for comparing the present models were calculated with the aid of the following equations:

$$
\begin{gathered}
E_{M D}=\frac{100}{N} \sum_{i=1}^{N} \frac{\left|M_{R, e x, i}-M_{R, p r e, i}\right|}{M_{R, \exp , i}} \\
E_{R M S}=\left[\frac{1}{N} \sum_{i=1}^{N}\left(M_{R, e x, i}-M_{R, p r e, i}\right)^{2}\right]^{1 / 2} \\
\chi^{2}=\frac{\sum_{i=1}^{N}\left(M_{R, e x, i}-M_{R, p r e, i}\right)^{2}}{N-z}
\end{gathered}
$$

where $M_{R, e x, i}=i^{\text {th }}$ experimental dimensionless moisture ratio, $M_{R, p r e, i}=i^{\text {th }}$ predicted dimensionless moisture ratio, $N=$ number of observations, and $z=$ number of constants (Madamba et al., 1996; Martin et al., 2001).

The model fit with the experimental data was primarily checked using $R^{2}$. The goodness of fit was also checked using $E_{M D}, E_{R M S}$, and $\chi^{2}$ parameters (Sacilik et al., 2006; Sacilik and Elicin, 2006).

\section{Results and Discussion}

Time-dependent variations in the moisture contents of the samples at different drying temperatures $\left(54,61,68\right.$, and $\left.75{ }^{\circ} \mathrm{C}\right)$ are presented in Fig. 2. As shown in Fig. 2, the moisture content of the final products with an initial moisture content of $82.33 \%$ d.b. varied between $12 \%$ and $20 \%$ d.b. As expected, there was a continuous decrease in the moisture contents with time. The time elapsed from the initial to the final moisture contents was measured as 2040, 1350, 1050, and $930 \mathrm{~min}$ for air-drying temperatures of $54,61,68$, and $75^{\circ} \mathrm{C}$, respectively. Previous researchers also reported decreasing drying times with increasing air-drying temperatures for wheat (Mohapatra and Rao, 2005), eggplant (Ertekin and Yaldiz, 2004), olive cake (Doymaz et al., 2004), hazelnut (Özdemir and Devres, 1999), and einkorn (Sacilik, et al., 2010).

Moisture content-dependent drying rates at different air-drying temperatures $(54,61$, 68 , and $75{ }^{\circ} \mathrm{C}$ ) are presented in Fig. 3. As shown in Fig. 3, drying curves did not have constant rates; instead, they had decreasing rates. Decreasing rates indicated increased drying rates with increased air-drying temperatures. Previous researchers also indicated the air-drying temperature as the primary factor in the drying rates of hazelnut (Özdemir and Devres, 1999), red pepper

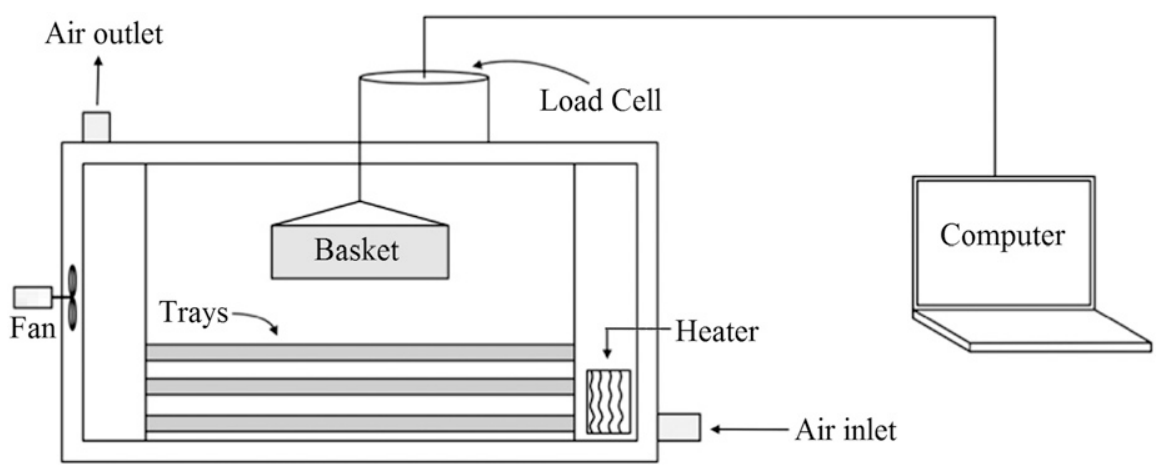

Fig. 1. Schematic diagram of the laboratory-scale convective hot-air dryer.

Table 1. Thin-layer drying models used to generate drying curves.

\begin{tabular}{llll}
\hline Model no. & Model name & \multicolumn{1}{c}{ Model } & \multicolumn{1}{c}{ References } \\
\hline 1 & Page & $M_{R}=\exp \left(-k t^{m}\right)$ & Agrawal and Singh (1977) \\
2 & Logarithmic & $M_{R}=a \exp (-k t)+c$ & Yagcioglu et al. (1999) \\
3 & Two-term & $M_{R}=a \exp (-k t)+b \exp \left(-k_{0} t\right)$ & Henderson (1974) \\
4 & $\begin{array}{c}\text { Approximation } \\
\text { of diffusion }\end{array}$ & $M_{R}=a \exp (-k t)+(1-a) \exp (-k b t)$ & Yaldız and Ertekin (2001) \\
& Midilli et al. & $M_{R}=a \exp \left(-k t^{m}\right)+b t$ & \\
5 & &
\end{tabular}

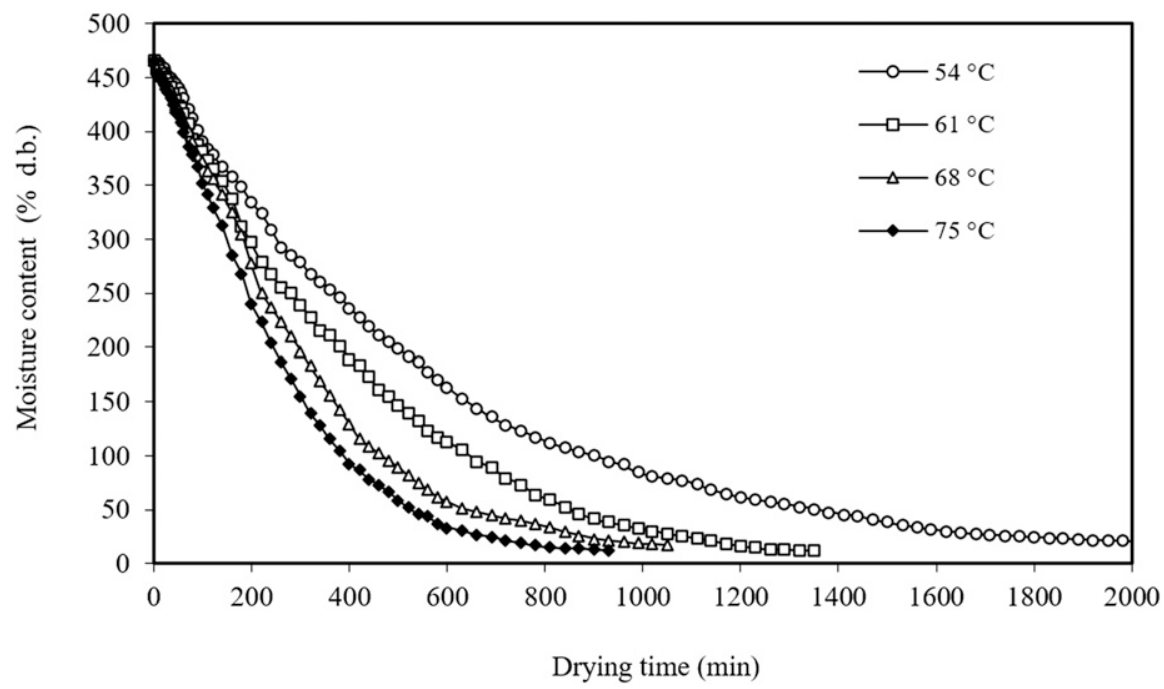

Fig. 2. Effects of air-drying temperatures on the moisture content of blackberry fruits.

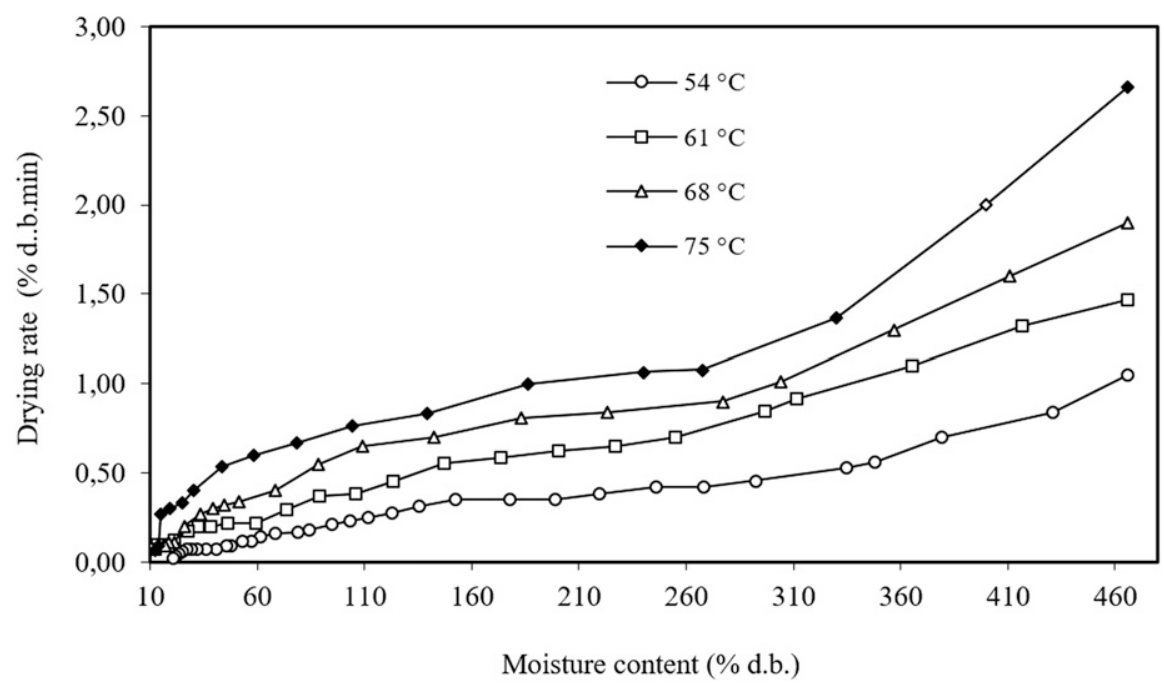

Fig. 3. Effects of air-drying temperatures on drying rate of blackberry fruits. 
Table 2. Model parameters of five different drying models for the hot-air drying of blackberry fruits.

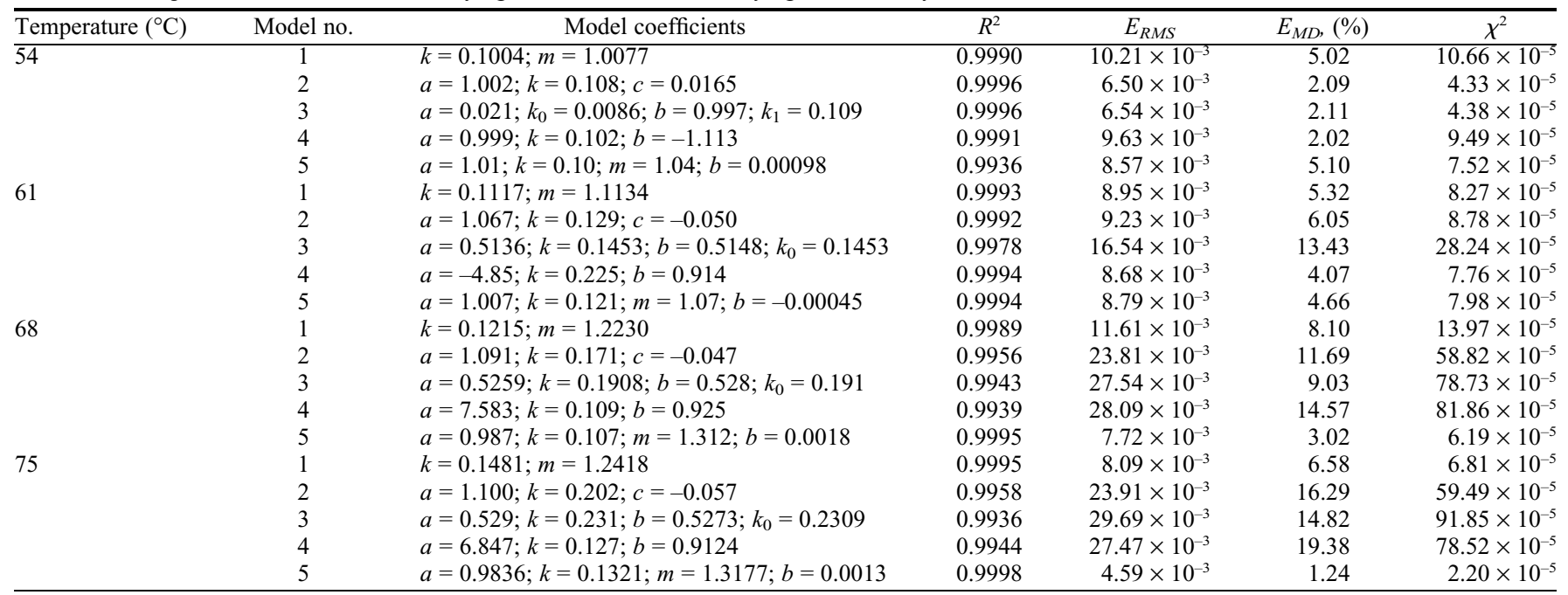

(Akpinar et al., 2003), and prickly pear peel (Lahsasni et al., 2004). Drying rates decreased with time. Greater temperatures yielded greater drying rates; therefore, reduced drying durations because of heat transfer and water migration were accelerated with increasing air-drying temperatures. The present findings are in compliance with the results of previous studies (Condori et al., 2001; Ertekin and Yaldiz, 2004; Pezzutti and Crapiste, 1997).

A nonlinear regression analysis was used to identify a best-fitting model for experimental data, and $R^{2}, E_{M D}, E_{R M S}$, and $\chi^{2}$ parameters were used to assess the goodness of fit (Table 2). $R^{2}$ values of the models varied between 0.9936 and $0.9998, E_{M D}$ values varied between 1.24 and $19.38, E_{R M S}$ values varied between $4.59 \times 10^{-3}$ and $29.69 \times 10^{-3}$, and $\chi^{2}$ values varied between $2.20 \times 10^{-5}$ and $91.85 \times 10^{-5}$ (Table 2). The $E_{M D}$ values of the Page and Midilli et al. models were less than $10 \%$, which was within the acceptable range. The greatest $R^{2}$ and the least $E_{M D}, E_{R M S}$, and $\chi^{2}$ values were observed in the Midilli et al. model. Therefore, the Midilli et al. model was considered the best-fitting model for experimental data gathered from the hot-airdrying experiments of blackberry fruits.

Variations in the experimental and Midilli et al. model predicted moisture contents at different air-drying temperatures $(54,61,68$, and $75{ }^{\circ} \mathrm{C}$ ) (Fig. 4). There was good conformity between the experimental and predicated data. Such conformity proved the goodness of fit of the Midilli et al. model for the experimental data.

The drying process for blackberry fruits exhibited decreasing rates, and liquid diffusion was the controlling parameter of the process. In this case, Fick's second law was used to describe the drying behavior of blackberry fruits. Fick's second law (presented here) assumed that moisture migration was realized through diffusion, shrinkage was negligible, and diffusion coefficients and temperatures were constant (Crank, 1975):

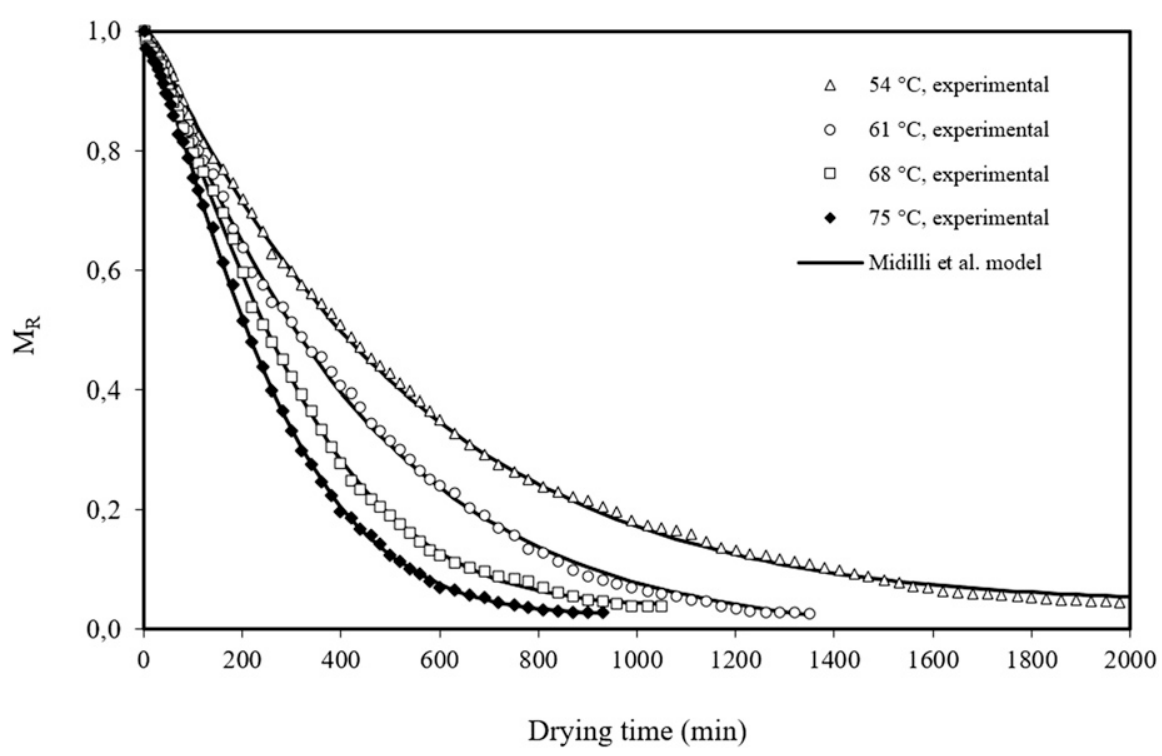

Fig. 4. Comparison of experimental and model (Midilli et al.) predicted moisture contents at different air temperatures.

$$
\begin{aligned}
M_{R} & =\frac{M-M_{e}}{M_{0}-M_{e}} \\
& =\frac{6}{\pi^{2}} \sum_{n=1}^{\infty} \frac{1}{n^{2}} \exp \left(\frac{-n^{2} \pi^{2} D_{e f f} t}{R_{e}^{2}}\right)
\end{aligned}
$$

In the case of long drying durations, Eq. (5) can be reduced to $M / M_{0}$ because $M_{e}$ is smaller than $M$ and $M_{0}$; therefore, it can be neglected. Then, the log form of Eq. (5) can be written as:

$$
\ln \frac{M}{M_{0}}=\ln \left(\frac{6}{\pi^{2}}\right)-\left(\frac{\pi^{2} D_{e f f} t}{R_{e}^{2}}\right)
$$

where $R_{e}=$ equivalent radius of dried blackberry fruits and $D_{\text {eff }}=$ effective diffusivity $\left(\mathrm{m}^{2} \cdot \mathrm{s}^{-1}\right)$.

Experimental data were plotted $\left(\ln M_{R}\right.$ vs. drying time) to obtain diffusion coefficients. The resultant plot yielded a straight line, and the slope of that straight line was expressed as:
Slope $=\frac{\pi^{2} D_{e f f}}{R_{e}^{2}}$

Effective diffusivity values at different airdrying temperatures $\left(54,61,68\right.$, and $\left.75{ }^{\circ} \mathrm{C}\right)$ were calculated as $2.75,4.69,5.72$, and $7.25 \times$ $10^{-10} \mathrm{~m}^{2} \cdot \mathrm{s}^{-1}$, respectively. Air-drying temperatures had significant effects on the effective diffusivity values. Increasing $D_{\text {eff }}$ values were observed with increasing air-drying temperatures because of accelerated moisture diffusion at greater temperatures. The present $D_{\text {eff }}$ values were within the specified ranges $\left(10^{-9}-10^{-11} \mathrm{~m}^{2} \cdot \mathrm{s}^{-1}\right)$. Maskan and Gogus (1998) reported $D_{\text {eff }}$ values between $2.32 \times$ $10^{-10} \mathrm{~m}^{2} \cdot \mathrm{s}^{-1}$ and $2.76 \times 10^{-10} \mathrm{~m}^{2} \cdot \mathrm{s}^{-1}$ for mulberries at 60 to $80{ }^{\circ} \mathrm{C}$. Doymaz (2004a) reported $D_{\text {eff }}$ values between $2.17 \times 10^{-10} \mathrm{~m}^{2} \cdot \mathrm{s}^{-1}$ and $2.40 \times 10^{-10} \mathrm{~m}^{2} \cdot \mathrm{s}^{-1}$ for plums at a drying temperature of $60{ }^{\circ} \mathrm{C}$ and air velocity of $1.2 \mathrm{~m} \cdot \mathrm{s}^{-1}$. Doymaz (2004b) reported that the 


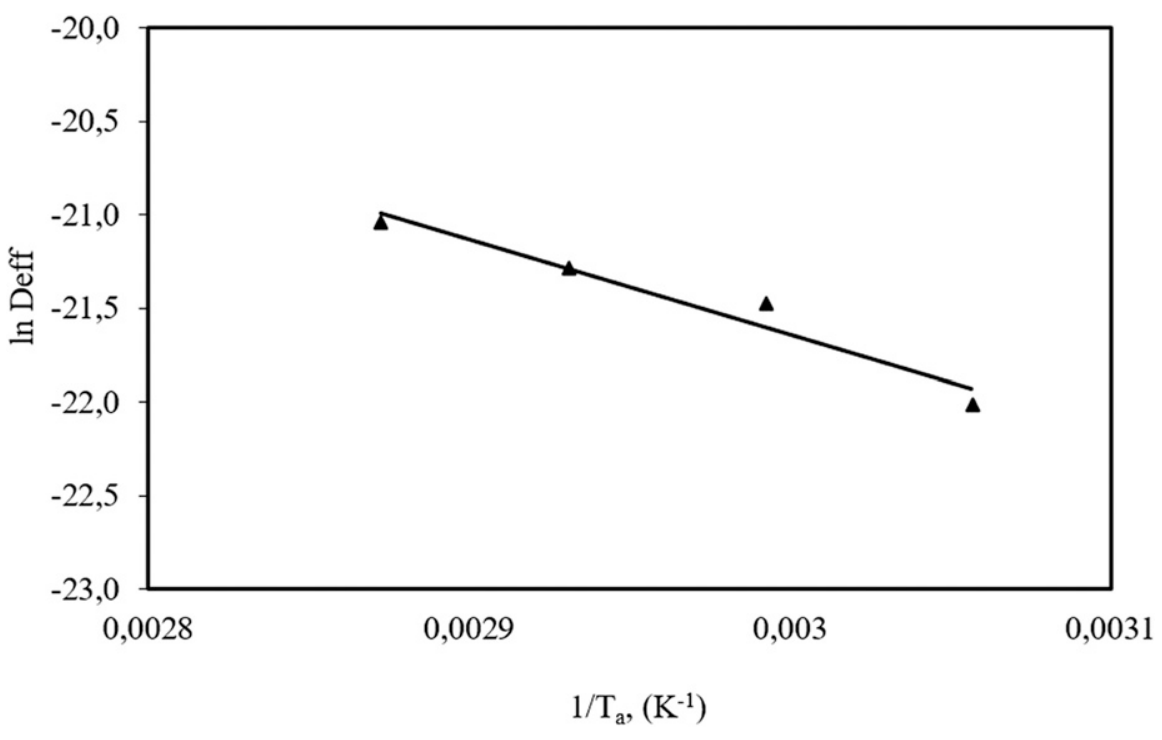

Fig. 5. Arrhenius-type relationships between effective diffusivity and absolute temperatures.

$D_{\text {eff }}$ value was $2.231 \times 10^{-10} \mathrm{~m}^{2} \cdot \mathrm{s}^{-1}$ for mulberries at $50{ }^{\circ} \mathrm{C}$. Sacilik and Elicin (2006) reported $D_{\text {eff }}$ values between $2.27 \times$ $10^{-10} \mathrm{~m}^{2} \cdot \mathrm{s}^{-1}$ and $4.97 \times 10^{-10} \mathrm{~m}^{2} \cdot \mathrm{s}^{-1}$ for organic apples at 40 to $60{ }^{\circ} \mathrm{C}$. Sacilik at al. (2006) reported $D_{\text {eff }}$ values between $2.66 \times$ $10^{-10} \mathrm{~m}^{2} \cdot \mathrm{s}^{-1}$ and $4.56 \times 10^{-10} \mathrm{~m}^{2} \cdot \mathrm{s}^{-1}$ for Üryani plum at 50 to $70{ }^{\circ} \mathrm{C}$. Finally, Doymaz (2007) reported $D_{\text {eff }}$ values between $4.75 \times$ $10^{-10} \mathrm{~m}^{2} \cdot \mathrm{s}^{-1}$ and $7.98 \times 10^{-10} \mathrm{~m}^{2} \cdot \mathrm{s}^{-1}$ for sour cherries at 55 to $65{ }^{\circ} \mathrm{C}$. The present $D_{\text {eff }}$ values for blackberry fruits were in good compliance with the previous values reported for various other fruit species.

The Arrhenius equation can be used to correlate effective diffusivity with air-drying temperatures as described:

$$
D_{\text {eff }}=D_{0} \exp \left(-\frac{E_{a}}{R T_{a}}\right)
$$

where $D_{0}=$ pre-exponential factor $\left(\mathrm{m}^{2} \cdot \mathrm{s}^{-1}\right)$, $E_{a}=$ activation energy $\left(\mathrm{kJ} \cdot \mathrm{mol}^{-1}\right), R=$ universal gas constant $\left(\mathrm{kJ} \cdot \mathrm{mol}^{-1} \cdot \mathrm{K}^{-1}\right)$, and $T_{a}=$ absolute air temperature $(\mathrm{K})$.

The slope of $\ln \left(D_{\text {eff }}\right)$ vs. the $1 /$ T plot can be used to obtain activation energy values (Fig. 5). The resulting plot yielded a straight line and indicated Arrhenius dependence on temperature. The temperature dependence of $D_{\text {eff }}$ values can be expressed as:

$$
\begin{aligned}
D_{e f f}= & 1.665 \times 10^{-3} \exp \left(-\frac{5081.73}{T}\right) \\
& \times\left(R^{2}=0.9502\right)
\end{aligned}
$$

Using Eq. (9), the activation energy was calculated as $42.25 \mathrm{~kJ} \cdot \mathrm{mol}^{-1}$. The present value complied with the specified ranges of 12.7 to $110 \mathrm{~kJ} \cdot \mathrm{mol}^{-1}$ for various fruit species (Zogzas et al., 1996).

\section{Conclusions}

The present findings revealed that dry curves of blackberry fruits were largely dependent on air-drying temperatures. Decreasing the drying durations were observed with increasing air-drying temperatures. Drying durations to reduce the initial moisture content of the fruits to the desired level were observed as 2040, 1350, 1050, and $930 \mathrm{~min}$ at air-drying temperatures of 54 , 61, 68, and $75{ }^{\circ} \mathrm{C}$, respectively. Effective diffusivity $\left(D_{\text {eff }}\right)$ values at specified airdrying temperature ranges $\left(54\right.$ to $75{ }^{\circ} \mathrm{C}$ ) varied between 2.75 and $7.25 \times 10^{-10} \mathrm{~m}^{2} \cdot \mathrm{s}^{-1}$. The activation energy $\left(E_{a}\right)$ was calculated as $42.25 \mathrm{~kJ} \cdot \mathrm{mol}^{-1}$. The present models (Page, logarithmic, two-term, approximation of diffusion, and Midilli et al.) were all found to be sufficient to obtain the model drying characteristics of blackberry fruits. However, among these models, the Midilli et al. model, with a mean relative percent deviation $\left(E_{M D}\right)$ of less than $10 \%$, had the best fit for the experimental data.

\section{Literature Cited}

Agrawal, Y.C. and R.D. Singh. 1977. Thin layer drying studies on short grain rice. ASAE Paper No: 3531 ASAE, St. Joseph, MI.

Akpinar, E.K., Y. Bicer, and C. Yildiz. 2003. Thin layer drying of red pepper. J. Food Eng. 59(1):99-104.

AOAC. 1990. Official method of analysis. Association of Official Analytical Chemists (No 934.06), Washington, DC.

Atungulu, G., Y. Nishiyama, and S. Koide. 2004. Electrode configuration and polarity effects on physiochemical properties of electric field treated apples post-harvest. Biosyst. Eng. 87(3): 313-323.

Condori, M., R. Echazu, and L. Saravia. 2001. Solar drying of sweet pepper and garlic using the tunnel greenhouse drier. Renew. Energy 22(4):447-460. Oxford University Press, London.

Diamente, L.M. and P.A. Munro. 1993. Mathematical modeling of the thin layer solar drying of sweet potato slices. Sol. Energy 51(4):271276.
Crank, J. 1975. Mathematics of Diffusions. 2nd ed.
Doymaz, I. 2004a. Effect of dipping treatment on air drying of plums. J. Food Eng. 64(4):465470.

Doymaz, I. 2004b. Drying kinetics of white mulberry. J. Food Eng. 61(3):341-346.

Doymaz, I. 2007. Influence of pretreatment solution on the drying of sour cherry. J. Food Eng. 78(2):591-596.

Doymaz, I., O. Gorel, and N.A. Akgun. 2004. Drying characteristics of the solid by-product of olive oil extraction. Biosyst. Eng. 88(2): 213-219.

Ertekin, C. and O. Yaldiz. 2004. Drying of eggplant and selection of a suitable thin layer drying model. J. Food Eng. 63(3):349-359.

Henderson, S.M. 1974. Progress in developing the thin-layer drying equation. Transactions of the ASAE 17:1167-1168/1172.

Krokida, M.K. and D. Marinos-Kouris. 2003. Rehydration kinetics of dehydrated products. J. Food Eng. 57(1):1-7.

Lahsasni, S., M. Kouhila, M. Mahrouz, A. Idlimam, and A. Jamali. 2004. Thin layer convective solar drying and mathematical modelling of prickly pear peel (Opuntia ficus indica). Energy 29(2):211-224.

Madamba, P.S., R.H. Driscoll, and K.A. Buckle. 1996. The thin-layer drying characteristics of garlic slices. J. Food Eng. 29(1):75-97.

Martin, M.B.S., J.I. Mate, T. Fernandez, and P. Virseda. 2001. Modelling adsorption equilibrium moisture characteristics of rough rice. Dry. Technol. 19(3\&4):681-690.

Maskan, M. 2000. Microwave/air and microwave finish drying of banana. J. Food Eng. 44(2): 71-78.

Maskan, M. and F. Gogus. 1998. Sorption isotherms and drying characteristics of mulberry (Morus alba). J. Food Eng. 37(4):437-449.

Midilli, A., H. Kucuk, and Z. Yapar. 2002. A new model for single-layer drying. Dry. Technol. 20(7):1503-1513.

Mohapatra, D. and P.S. Rao. 2005. A thin layer drying model of parboiled wheat. J. Food Eng. 66(4):513-518.

Moure, A., J.M. Cruz, D. Franco, J.M. Domìnguez, J. Sineiro, H. Domìnguez, M.A. José Núñez, and J.C. Parajó. 2001. Natural antioxidants from residual sources. Food Chem. 72(2):145171.

Özdemir, M. and Y.O. Devres. 1999. The thin layer drying characteristics of hazelnuts during roasting. J. Food Eng. 42(4):225-233.

Pezzutti, A. and G.H. Crapiste. 1997. Sorptional equilibrium and drying characteristics of garlic. J. Food Eng. 31(1):113-123.

Reáteguia, J.L.P., A.P.F. Machado, G.F. Barbero, C.A. Rezende, and J. Martínez. 2014. Extraction of antioxidant compounds from blackberry (Rubus sp.) bagasse using supercritical $\mathrm{CO}_{2}$ assisted by ultrasound. J. Supercrit. Fluids 94 : 223-233.

Rickman, J.C., D.M. Barrett, and C.M. Bruhn. 2007. Review: Nutritional comparison of fresh, frozen and canned fruits and vegetables. Part 1. Vitamins $\mathrm{C}$ and $\mathrm{B}$ and phenolic compounds. J. Sci. Food Agr. 87:930-944.

Sacilik, K. and A.K. Elicin. 2006. The thin layer drying characteristics of organic apple slices. J. Food Eng. 73(3):281-289.

Sacilik, K., A.K. Elicin, and H.G. Unal. 2006. Drying kinetics of Üryani plum in a convective hot-air dryer. J. Food Eng. 76(3):362368 .

Sacilik, K., Y.B. Yurtlu, and H.G. Unal. 2010. Thin layer convective drying and mathematical modeling of einkorn. Conference Proceedings $-4^{\text {th }}$ International Conference, 
TAE 2010: Trends in Agricultural Engineering Prague; Czech Republic; 7-10 Sept. 2010, p. $540-548$.

Tunde-Akintunde, T.Y., T.J. Afolabi, and B.O. Akintunde. 2005. Influence of drying methods on drying of bell-pepper (Capsicum annuum). J. Food Eng. 68(4):439-442.

Wu, R., B. Frei, J.A. Kennedy, and Y. Zhao. 2010. Effects of refrigerated storage and processing technologies on the bioactive compounds and antioxidant capacities of 'Marion' and 'Evergreen' blackberries. Lebensm. Wiss. Technol. 43(8):1253-1264.

Yagcioglu, A., A. Degirmencioglu, and F. Cagatay. 1999. Drying characteristics of laurel leaves under different drying conditions. In Proceedings of the 7th International Congress on Agricultural Mechanization and Energy 565-569, 26-27 May, Adana, Turkey.

Yaldız, O. and C. Ertekin. 2001. Thin layer solar drying some different vegetables. Dry. Technol. 19(3):583-596.

Zogzas, N.P., Z.B. Maroulis, and D. MarinosKouris. 1996. Moisture diffusivity data compilation in foodstuffs. Dry. Technol. 14: 2225-2253. 